\title{
Peningkatan Produktivitas Dan Kreatifitas Kelompok Pengelola Bank Sampah
}

\author{
Nuril Lutvi Azizah1, Cindy Cahyaning Astuti2, Metatia Intan Mauliana ${ }^{3}$ \\ ${ }^{1}$ Fakultas Sains dan Teknologi, Universitas Muhammadiyah Sidoarjo \\ ${ }^{2}$ FKIP, Universitas Muhammadiyah Sidoarjo \\ ${ }^{3}$ Fakultas Sains dan Teknologi, Universitas Muhammadiyah Sidoarjo \\ Email: 1nurillutviazizah@umsida.ac.id,² cindy.cahyaning@umsida.ac.id, \\ 3metatialiana@umsida.ac.id
}

\begin{abstract}
Pogar is a village located in Bangil District, Pasuruan Regency. The majority of the people earns as farmers and small home indutsries. The most commonly found anorganic rubbish is plastic, found around $400 \mathrm{~kg}$ per month in this village. The plastic waste can be recycled to be diverse. However, there are a number of things that have become partners' problems, which are not insufficient capital for the purchase of equipment, increasing community creativity through related activities, and the supply of garbage must always be large and in constant amounts. Regarding the main problem described, this program will offer solutions that are expected to help reduce the problems faced by partners. The method that will be used in addition to Socialization or Counseling so that the community is more creative and productive as well as the procurement of equipment and goods that can support partners in processing waste recycling into valuable products. We also market their products through the internet and provide tutorials on making samples of products online or offline. The result of the services is that groups can create creative products and utilize anorganic waste around their environment, as well as market the products they have produced.
\end{abstract}

Keywords: Recycled, Creative, Productive, Socialization

\section{Pendahuluan}

Pogar merupakan kelurahan yang terletak di Kecamatan Bangil Kabupaten Pasuruan. Masyarakat desa ini mayoritas bermata pencaharian sebagai petani, pedagang, dan home industry kecil. Seperti halnya permasalahan yang dihadapi di desa yang padat penduduk pada umumnya, sampah merupakan permasalahan utama yang menjadi persoalan lingkungan yang harus dicarikan jalan keluar. ${ }^{1}$ Produksi sampah yang terus meningkat

${ }^{1}$ Desiana, “Analisa Program Bank Sampah”. Volume 01, 2013, pp 01-07. 
seiring dengan bertambahnya jumlah penduduk, perubahan pola konsumsi masyarakat, dan gaya hidup masyarakat, telah meningkatkan jumlah timbunan sampah, jenis, dan keberagaman karakteristik sampah. Meningkatnya volume timbunan sampah memerlukan pengelolaan yang harus segera diatasi. Berdasarkan sumber data dari kelurahan Pogar, sebanyak 17\% sampah berasal dari pasar, 23\% berasal dari sampah rumah tangga dan umum, 25\% berasal dari sampah perdagangan dan industri, 5\% dari sampah pertanian, dan sisanya berasal dari kegiatan home industry. Untuk mengatasi permasalahan ini, pihak kelurahan yang digagas oleh Bapak Bambang selaku Bapak Lurah Pogar mendirikan komunitas bank sampah yang bermaksud untuk mengumpulkan dan mendaur ulang sampah plastik yang bisa di daur ulang (recycle). Pengelolaan sampah ini dimaksudkan dengan tujuan untuk meningkatkan kesehatan masyarakat, kualitas lingkungan, serta harapannya menjadikan sampah sebagai sumberdaya.

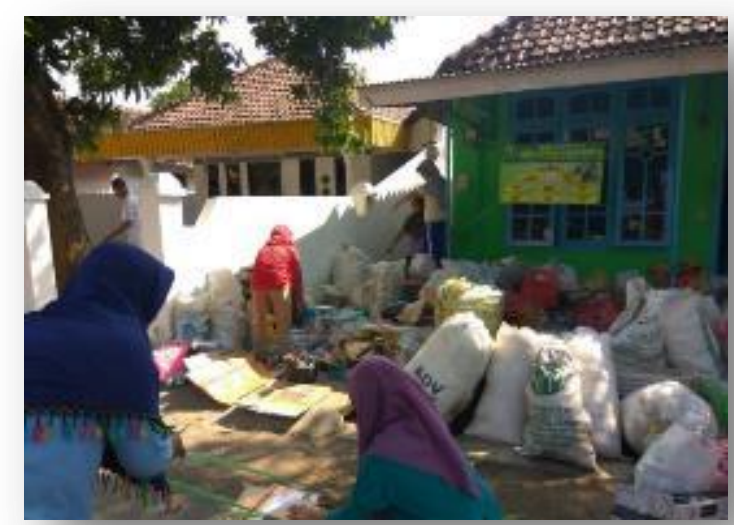

\section{Gambar 1. Kondisi Bank Sampah "Pogar Bangkit" (Sumber: Dokumetasi, 2019)}

Kelompok pengelola bank sampah dengan nama "POGAR BANGKIT" ini didirikan di kelurahan Pogar, Kecamatan Bangil, Kabupaten Pasuruan pertama kali pada tahun 2017 dengan tujuan hanya mengumpulkan sampah plastik yang bisa diperjual belikan kembali kepada pengepul sampah setiap bulannya untuk tambahan kas desa dan untuk pengelola. Akan tetapi 
keuntungan yang diperoleh tidak maksimal meskipun sampah yang dihasilkan sudah cukup banyak. Selain itu bank sampah juga menerapkan sistem 3R yaitu reduce-mengurangi, reuse-menggunakan, dan recyclemendaur ulang dengan sistem ramah lingkungan. ${ }^{2}$

Permasalah mitra yang diangkat pada program pengabdian masyarakat ini adalah sampah plastik yang telah dikumpulkan di desa ini sudah cukup banyak, akan tetapi kurangnya penerapan sistem 3R pada pengelolaan sampah yang dilakukan yaitu reduce-mengurangi, reuse-menggunakan, dan recycle-mendaur ulang terutama dalam hal mendaur ulang sampah plastik. Permasalahan lain yang dihadapi oleh kelompok pengelola bank sampah adalah masih kurangnya kreatifitas dalam pembuatan karya seni yang dibentuk dari sampah plastik yang telah didapatkan. Selain itu, diperlukan pula media digital untuk membantu mempromosikan dan meningkatkan kreatifitas. $^{3}$

Pembuatan konten adalah proses mengolah data-data digital menjadi sebuah informasi yang dapat diakses oleh masyarakat. Media digital yang dapat diolah bisa berupa artikel, foto, bahkan video. ${ }^{4}$

\section{Metode}

Tahap penyelesaian permasalahan dilakukan dengan menyelesaikan permasalahan mitra antara lain observasi dan identifikasi kelemahan mitra, penawaran solusi pada mitra, perancangan sistem solutif, sosialisasi, monitoring dan evaluasi.

\footnotetext{
2 Desiana, “Analisa Program Bank Sampah”. Volume 01, 2013, pp 01-07,

3 Truyens, M. \& Van Eecke, P., 'Liability of domain name registries: Don't shoot the messenger, Journal of Computer Law \& Security Review, Volume 32, Issue 2, pp 327-344, 2016.

${ }^{4}$ Puspitasari, L. \& Ishii, K., 'Digital divides and mobile Internet in Indonesia: Impact of smartphones', Journal of Telematics and Informatics, Volume 33, Issue 2, pp 472-483, 2016.
} 
1. Metode Pelaksanaan Sosialisasi Awal

Pada pelaksanaan program pengabdian masyarakat ini dilakukan sosialisasi atau penyuluhan awal mengenai sampah, kategori sampah dan bagaimana cara memanfaatkan sampah anorganik.

2. Peningkatan Kreatifitas dan Pengadaan Alat Penunjang Peningkatan kreatifitas yang dilakukan pada program ini dengan memberikan alat penunjang untuk mengolah sampah anorganik menjadi barang kraetifitas yang mempunyai seni dan nilai jual.

3. Pembuatan Konten Promosi dan Tutorial

Pada Tahap Terakhir program ini yaitu membuatkan konten tutorial dan promosi berbasis internet. Tutorial dilakukan secara online melalui video tutorial, dan pengembangan produk melalui web, dan sosial media lainnya, sedangkan melalui offline dengan langsung mendatangkan tenaga yang mempunyai keahlian dibidang lingkungan mengenai pengolahan sampah anorganik dan pemanfaatannya. Cara ini dilakukan secara service learning dan partnership dengan pihak yang saling berkaitan.

\section{Hasil dan Diskusi}

Tahapan ini merupakan hasil dalam kegiatan yang dilakukan selama program pengabdian masyarakat yang telah dilakukan.

1. Pelaksanaan Sosialisasi Awal

Untuk sosialisasi awal, dilakukan pertemuan yang cakupan masyarakatnya meliputi perwakilan desa yang disini adalah Lurah desa Pogar, kelompok pengelola bank sampah "Pogar Bangkit" dan Ibu-ibu PKK Pogar. Disini dimaksudkan adanya perwakilan dari masing-masing kelompok masyarakat agar lebih efektif dan nantinya akan membantu dalam mengkoordinasi bank sampah yang telah berjalan sebelumnya. Dalam sosialisasi awal ini dijelaskan mengenai program bank sampah serta manfaat yang diperoleh apabila bergabung di bank sampah. 


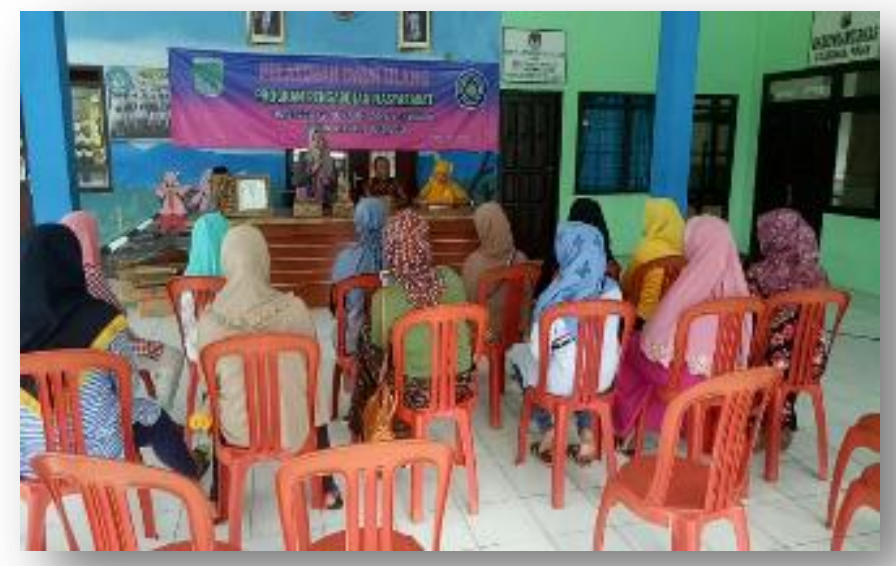

\section{Gambar 2. Sosialisasi Awal Pegabdian}

(Sumber: Dokumentasi, 2019)

Sosialisasi yang dilakukan, mengundang sebanyak 20 kader dari PKK dan Kelompok Pengelola Bank Sampah, dan peserta yang datang sebanyak 15 orang.

2. Peningkatan Kreatifitas melalui Tutorial

Setelah sosialisasi dengan presentasi dan ceramah, kegiatan selanjutnya adalah peningkatan kreatifitas via online melalui video-video yang berkaitan dengan cara-cara nenbuat barang kreatifitas dari sampah plastik seperti pada Gambar 3.

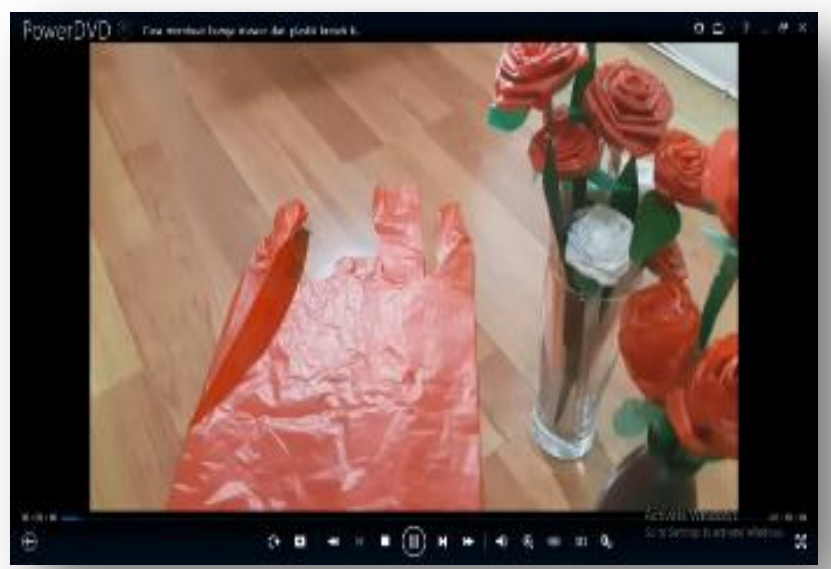

Gambar 3. Pemutaran Video Mengenai Pembuatan Bunga Hias (Sumber: Dokumentasi, 2019) 


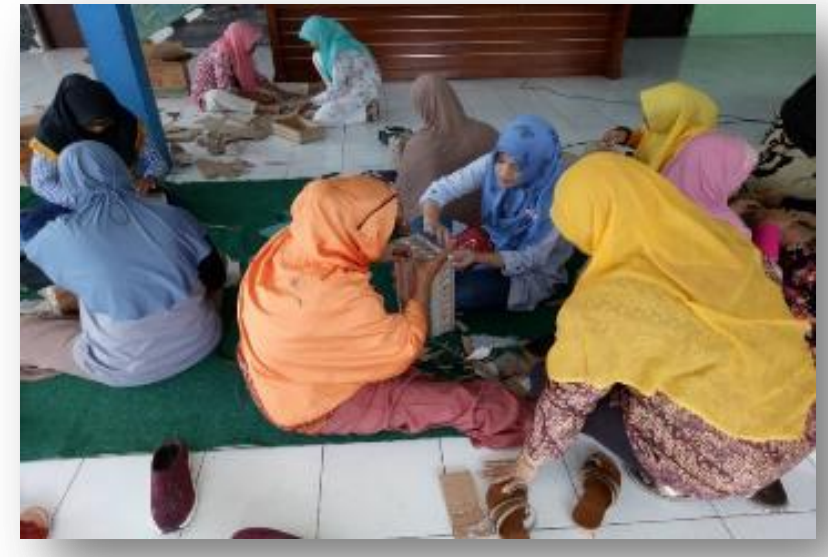

\section{Gambar 4. Praktek Langsung Pembuatan Barang Kreasi} (Sumber: Dokumentasi, 2019)

Kegiatan kedua yaitu penyuluhan yang dilakukan secara offline oleh narasumber yang telah berpengalaman. Narasumber yang diundang dalam kegiatan penyuluhan dan praktek langsung cara pembuatan ini adalah ibu Yuni. Ibu Yuni merupakan aktivis lingkungan di Kabupaten Pasuruan yang berkecimpung mulai Tahun 2010, sampai sekarang ibu Yuni aktif diundang sebagai narasumber diberbagai kegiatan lingkungan, dan memberikan pelatihan langsung praktek kepada masyarakat yang tertarik terhadap pembuatan barang kreasinya.

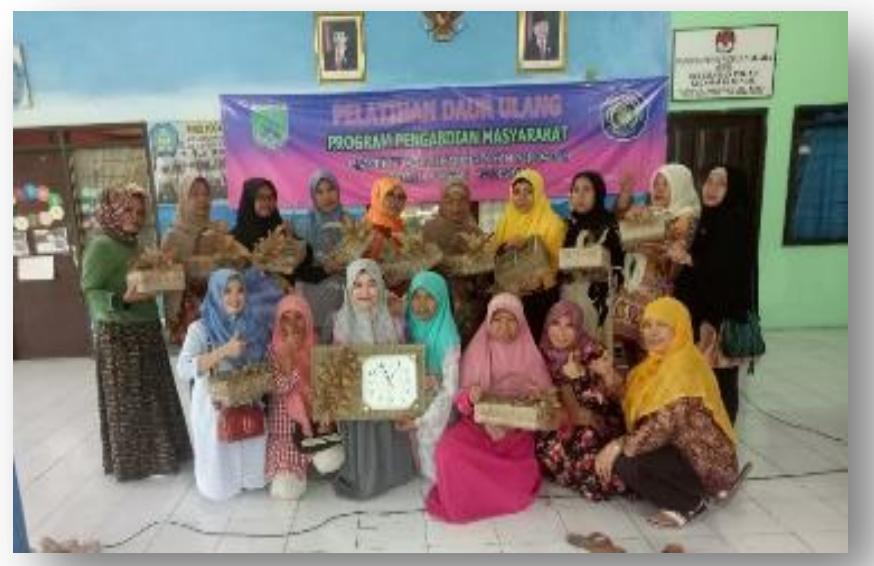

Gambar 5. Foto Akhir Pelatihan dan Praktek Para Kader dan Narasumber (Sumber: Dokumentasi, 2019) 
Pada pelatihan dan praktek ini, para kader bisa membuat dan mengambil hasil karya yang telah mereka hasilkan selama pelatihan.

Gambar 5. merupakan akhir dari pelatihan dan praktek yang dilakukan oleh pengusul abdimas, narasumber, dan beserta pelatihan dengan karya mereka masing-masing.

3. Monitoring dan Evaluasi

Monitoring dan evaluasi ini dilaukan dengan membangun konten berbasis internet guna mengetaui keberlanjutan program yang telah dilaksanakan. Pembuatan konten berbasis internet antara lain email dengan nama pogarbangkit@gmail.com , sosial media seperti facebook dengan nama account "Pogar Bangkit", Instagram dengan nama IG @pogarbangkit yang berisi kreasi pogar bangkit, youtube dengan salah satu link antara lain https://www.youtube.com/watch?v=qeif6rFVQZc. Berisi kegiatan sosialisasi dan kreasi Bank Sampah Pogar Bangkit. Web dengan nama Konten atau domain name yang telah kami sepakati dengan mitra diberi nama "pogarbangkit.wordpress.com" berisi kegiatan sosialisasi dan kagiatan apa saja yang ada di desa Pogar yang kesemuanya dapat dilakukan oleh mitra atas bimbingan tim abdimas.

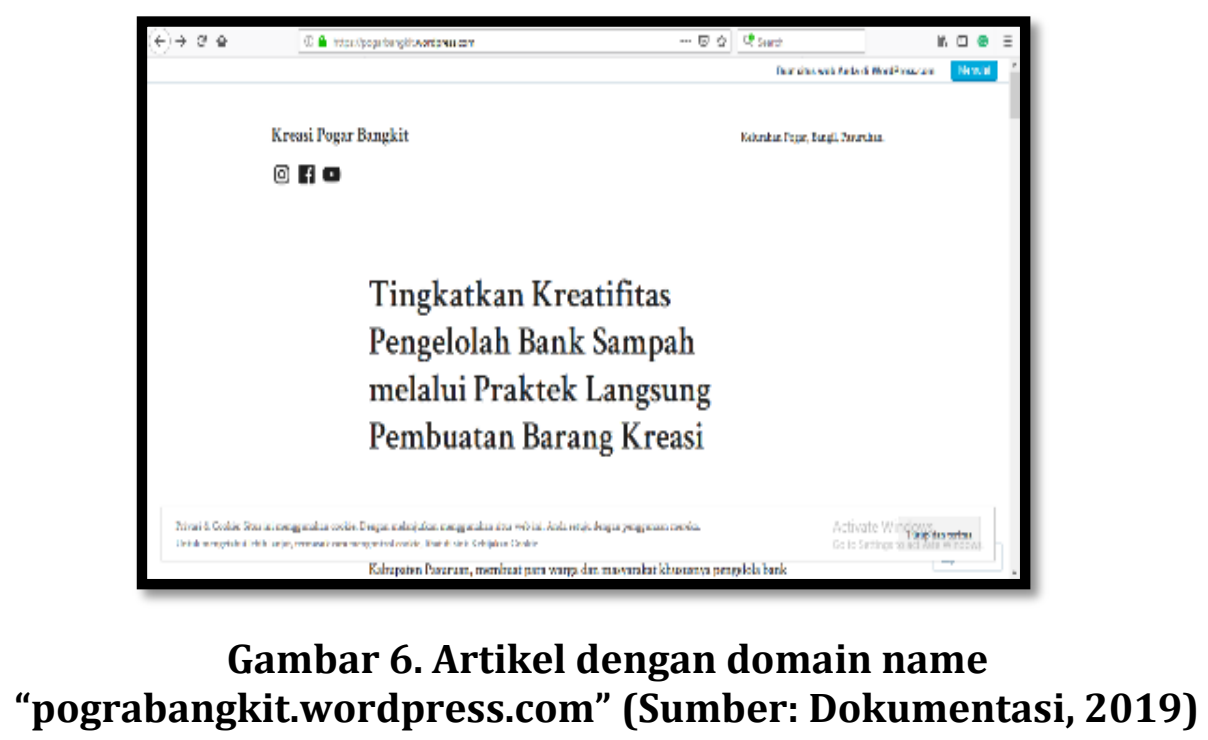




\section{Kesimpulan}

Produk yang dihasilkan selama evaluasi selama 4 bulan antaran lain wadah atau tempat minum kemasan gelas, tempat tisu, hiasan dinding, bunga plastik, tempat pensil dari botol bekas, dan tas dari kemasan minuman sachet. Berikut merupakan Tabel jumlah produk kreasi yang dihasilkan selama kurang lebih 4 bulan evaluasi:

Tabel 1. Evaluasi Produk Yang dihasilkan Kelompok Pengelola Bank Sampah

\begin{tabular}{|c|l|l|c|}
\hline No & Barang Kreasi yang dihasilkan & \multicolumn{1}{|c|}{ Jenis Sampah } & Jumlah \\
\hline 1. & Wadah minum kemasan gelas & Kardus/Kertas & 20 \\
\hline 2. & Tempat Tisu & Kardus/Kertas & 15 \\
\hline 3. & Hiasan Dinding & Kardus/Kertas & 3 \\
\hline 4. & Bunga Plastik & Sedotan, Kresek, Kawat & 10 \\
\hline 5. & Tempat Pensil/Sikat Gigi & Botol Minum & 10 \\
\hline 6. & Tas & Plastik kemasan minuman sachet & 2 \\
\hline
\end{tabular}

Sumber: Dokumentasi, 2019

Dalam keberlanjutan program, agar mengalami peningkatan secara konstan dan signifikan baik dalam hal pembuatan, peningkatan kreatifitas, promosi dan penjualan barang kreasi, diperlukan konsistensi dan kerjasama dari berbagai pihak. Dengan kerjasama antara masyarakat, pemerintah desa, dan kelompok pengelola bank sampah, diharapkan dapat meningkatkan substansi penggunaan sampah anorganik dan setidaknya dapat mengurangi, memanfaatkan, dan memiliki nilai jual kembali.

\section{Daftar References}

Desiana, “Analisa Program Bank Sampah". Jurnal Lingkungan dan Manajemen, Volume 01, pp 01-07, 2013.

Ghezzia, Antonio., et all., 'A role for startups in unleashing the disruptive power of social media', International Journal of Information Management, Volume 36, Issue 6, Part A, pp 1152-1159, 2016.

Puspitasari, L. \& Ishii, K., 'Digital divides and mobile Internet in Indonesia: Impact of smartphones', Journal of Telematics and Informatics, Volume 33, Issue 2, pp 472-483, 2016.

Truyens, M. \& Van Eecke, P., 'Liability of domain name registries: Don't shoot the messenger, Journal of Computer Law \& Security Review, Volume 32, Issue 2, pp 327-344. 2016. 